Hermano Castro 1

Fernanda Giannasi 2

Cyro Novello 1

\section{A luta pelo banimento do amianto nas Américas: uma questão de saúde pública}

The struggle to ban asbestos in the A mericas: an issue of public health
Abstract This article has the aim of rescuing the fight for the banishment of asbestos in A mericas. The authors emphasize the importance of the asbestos as a problem of Public $\mathrm{H}$ ealth, due to its carcinogenic potential to human health, passing through the constitution of nets of counterpower on behalf of the banishment of the fiber, pointing out the importance of social participation in this fight. The asbestos public policy of health, work and environment is pointed out as a central problem. There are some misconceptions in the field of W orker's $\mathrm{H}$ ealth on facing the risks and damages caused by asbestos/amiantos and it is very important not to restrict the surveillance only to workstation. The discussion must be conducted taking in account Environmental $\mathrm{H}$ ealth and $\mathrm{H}$ ealth Policies. The lack of public policy is viewed as responsible for turning invisible the problems related to asbestos in Brazil. Today, the victims of the fiber are not recognized as such and their rights are denied in several instances of the public power. We conclude that the fight of the society for the end of the use of this fiber and for the end of the countless diseases provoked by its use, it is configured in a political and social movement committed with the social transformation in the search for a society fairer, equalitarian and healthy.

Key words Amianthus, Asbestos, Public H ealth and Counterpowers
Resumo Este artigo tem como objetivo resgatar a luta pelo banimento do amianto ou asbesto nas A méricas. Destacando-se a importância do amianto como um problema de Saúde Pública, pelo seu potencial carcinogênico reconhecido para os seres humanos, perpassando pela constituição de redes como contrapoderes em prol do banimento dessa fibra nociva, ressaltando a partici pação social nessa luta. 0 problema do amianto nas discussões das políticas públicas de saúde, trabalho e meio ambiente ainda permanece pouco claro no campo da Saúde do Trabalhador. Ao restringir a apenas um único campo de atuação, reduz-se a atuação das vigilâncias, como se estivesse apenas limitado ao ambiente de trabaIho. É necessária então a discussão nos campos da Saúde Ambiental e da Saúde Publica. A ausência de políticas públicas contribui para a invisibilidade dos problemas relacionados ao amianto no Brasil. H oje, as vítimas do amianto não têm suas doenças reconhecidas, e seus direitos são negados em várias instâncias do poder público. Conclui-se que a luta pelo fim da utilização dessa fibra e a redução das doenças provocadas pela mesma configuram-se um movimento político comprometido com a transformação social na busca por uma sociedade mais justa, igualitária e sau dável. Palavras-chave Amianto, Asbesto, Saúde Pública, Contrapoderes 
Introdução à problemática do amianto nas discussões das políticas públicas de saúde, trabalho e meio ambiente

0 amianto ou asbesto é uma fibra de origem mineral, derivada de rochas metamórficas eruptivas, que por processo natural de recristalização transforma-se em material fibroso. Compõe-se de silicatos hidratados de magné sio, ferro, cálcio e sódio e se divide em dois grandes grupos: serpentinas (crisotila ou amianto branco) e anfibólios (tremolita, actinolita, antofilita, amosita e crocidolita, etc.).

É conhecido desde a Antigüidade pelo homem primitivo, que o misturava com barro para conferir propriedades de refratariedade aos utensílios domésticos. $\mathrm{N}$ a atualidade, é ainda muito utilizado como matéria-prima na maioria das indústrias dos países de economia periférica, principalmente, na produção de artefatos de cimento-amianto para a indústria da construção civil (telhas, caixas d'água, divisórias, painéis acústicos, forros e pisos, etc.) e em outros setores e produtos como guarnições de freios (lonas e pastilhas), juntas, gaxetas, revestimentos de discos de embreagem - no setor automotivo, tecidos, vestimentas especiais, pisos, tintas, revestimentos e isolamentos térmicos e acústicos, entre outros.

É considerado uma substância de comprovado potencial cancerígeno em quaisquer das suas formas ou em qualquer estágio de produção, transformação e uso. De acordo com a Organização M undial de Saúde (OMS), a crisotila está relacionada a diversas formas de doença pulmonar (asbestose, câncer pulmonar e mesotelioma de pleura e peritônio), não havendo nenhum limite seguro de exposição para o risco carcinogênico de acordo com o Critério 203, publicado pelo IPCS (International Programme on Chemical Safety)/W HO (Organização M undial da Saúde) (WH O, 1998). A O M S recomenda, complementarmente, que o uso do amianto seja substituído, sempre que possível, da mesma forma que a OIT (Organização Internacional do Trabalho) já o fizera em sua Convenção 162 de 1986.

No Brasil, o amianto tem sido usado em larga escala há muitas décadas. Estima-se que a população brasileira direta e ocupacionalmente exposta seja de 500.000 pessoas, das quais cerca de 20.000 são trabal hadores da indústria de exploração e transformação - mineração, cimento-amianto, materiais de fricção e outros. Há, entretanto, cerca de outros 300.000 traba-
Ihadores envolvidos em manutenção e reparos de sistemas de freio no país, segundo estimativa do Sindipeças (Sindicato Nacional da Indústria de Autopeças), e uma parcela desconhecida, de trabalhadores informais, principalmente, envolvidos na indústria da construção civil, em atividades como instalação de coberturas, caixas d'água, reformas, demolições, instalações hidráulicas, etc., que estão completamente à margem de qualquer proteção social e das incipientes políticas públicas de saúde do trabalhador. Segundo sindicatos dos trabal hadores, numa estimativa grosseira, estes trabaIhadores podem chegar a aproximadamente 500.000 em todo o país (Algranti, 2001).

Reveste-se, portanto, da maior gravidade essa questão no campo da Saúde do Trabalhador, no qual sequer se tem o mapa da população direta e ocupacional mente exposta no país. Quando partimos para uma análise mais ampla, envolvendo outros atores sociais, como familiares, usuários e habitantes do entorno da mineração e das usinas de ben eficiamento, os indireta, paraocupacional e ambientalmente expostos, o problema pode ter uma dimensão ainda mais grave.

Considerando-se a longa latência das doenças atribuídas ao amianto e a sua produção em larga escala no país, a partir da década de 1970, podemos considerar que o pico do adoecimento em nosso país se dará entre 2005-2015, como vimos ocorrer na Europa e nos Estados U nidos a partir do final dos anos 60.

\section{Amianto: uma questão de saúde pública}

É indiscutível que o amianto é uma ameaça para toda a população e que todo ser humano tem direito a um ambiente saudável e sem amianto. A associação entre a exposição ao amianto e doenças, incluindo o câncer, está bem documentada cientificamente há al gumas décadas (Castro et al., 2001).

A utilização do amianto se proliferou nos últimos 100 anos, acompanhando a industrialização e participando do processo produtivo de 3 mil produtos em todo o mundo.

Enfrentado a princípio como um problema do trabalho, relacionado exclusivamente aos trabal hadores expostos, logo o risco passou a ser entendido como um problema de Saúde Pública, em que a ameaça ultrapassava os limites da fábrica, atingindo a população indis- 
criminadamente. Diversos estudos mostraram que a fibra pode causar danos tanto aos familiares dos trabal hadores, que traziam as fibras para a residência, quanto para a população exposta devido ao manuseio de materiais contendo fibras de amianto.

A confusão no campo da Saúde do TrabaIhador tem sido freqüente no enfrentamento aos riscos e aos danos causados pelo asbesto/ amianto. Ao restringir a apenas um único campo de atuação, reduz-se sobremaneira a atuação das vigilâncias e o controle, como se o problema fosse apenas limitado ao ambiente de trabalho.

U m dos nossos objetivos é colocar elementos para esclarecer a inter-relação que existe entre Promoção da Saúde e a Saúde do TrabaIhador no campo da Saúde Pública. O conceito da Promoção de Saúde, definido no Relatório Lalonde, em 1974, no Canadá, estabelece quatro importantes pólos: a biologia humana, 0 sistema de organização dos serviços, o ambiente, que envolve o social e o estilo de vida, incluídos os riscos no trabal ho, e os padrões de consumo.

Embora não seja nosso objetivo discorrer sobre o tema, outro ponto importante é o conceito de Saúde do Trabalhador, que contempla a dimensão social na medida em que incorpora o trabalhador como sujeito das ações, nos ambientes de trabalho, dando densidade a todas as questões relacionadas à sociedade em geral. De acordo com Câmara e Galvão (1995), o crescimento da área de Saúde do Trabalhador, durante a década de 1980, abriu caminho para a incorporação da Saúde Ambiental, a partir da existência de questões do trabal ho, ambiente e o sistema de saúde, entendido e acolhido no próprio Sistema Ú nico de Saúde (SUS).

0 ambiente, incluindo o trabalho, é visto globalmente pela sociedade. Além disso, a conferência M undial pelo M eio Ambiente - UN CED/CNU MAD, realizada no Rio de Janeiro, em 1992, definiu que a Saúde Ambiental seria uma prioridade social para a Promoção da Saúde dos povos.

A saúde deve ser abordada de forma holística e integrada nas diversas formas do viver. Segundo Paim eFilho (1998), o fenômeno saúde é concebido como expressão do "modo de vida" (estilo e condições de vida), articulando dimensões relacionadas à reprodução biológica, à reprodução das relações ecológicas, que envolve a relação dos grupos com 0 ambiente e o trabal ho, à reprodução das formas de cons- ciência e comportamento e à reprodução das relações econômicas, onde se realizam a produção, distribuição e o consumo. As relações econômi cas serão retomadas mais à frente, contextualizando-as dentro do ambiente social.

D esta forma, passamos à compreensão do público, com a possibilidade de o risco atingir populações, causando danos à saúde das pessoas, quase sempre desinformadas quanto ao potencial desse risco. M endes (2001) chama a atenção para a ubiqüidade da exposição relacionada ao amianto/asbesto, em que as pessoas são freqüentemente expostas sem 0 saber $e$ com o adoecimento ocorrendo tempos após a liberação da fibra e em local distante da fonte de liberação. Da mesma forma, Freitas (2003) refere-se à ameaça e aos perigos ambientais para a Saúde Pública, tendo os riscos se multiplicado e expandido no espaço e também no tempo, atingindo casas, cidades e efeitos futuros sobre a vida.

N este ponto, Tarride (1998) assinala que a Saúde Pública assume como uma de suas funções a de modificar ou controlar as condições desfavoráveis do ambiente que afetam a saúde do homem. Aqui também novamente é trazida, por Tarride (1998), a dimensão social com uma abordagem totalizadora relacionada à saúde, não apenas incorporando o social, mas tratando a saúde como uma questão social.

Configura-se, assim, o papel dos movimentos sociais, que, através de vários modos, incluindo as ON Gs e as redes - a serem discutidas mais detal hadamente a seguir - , tendem a assumir plenamente o papel de defesa de uma sociedade saudável, integrando os conceitos de Justiça Ambiental como um direito humano fundamental. Como parte do elenco de ações que impeçam a construção social de grupos de excluídos ou discriminados ambientalmente por práticas condenáveis como o racismo ambiental, que condena e segrega em todo mundo parcela importante da sociedade a viver em ambientes degradados e sujeita à transferência de produtos e tecnologias desacreditadas e perigosas.

Tambellini e Câmara (1998) chamam a atenção para a possibilidade que o campo da saúde tem de intervenção concreta na realidade, tendo como objetos os processos de saúde e de doença nas coletividades. Ela dá uma amplitude às ações multidisciplinares, incorporando atores sociais e técnicos, articulando esses atores nas ações frente aos processos de trabalho e a sua interface com a saúde e a 
doença. Tambellini e Câmara (1998) ainda abordam a questão da saúde a partir do contexto bio-sócio-sanitário, no qual as relações econômicas, produtivas e sociais definem os impactos no ambiente e na sociedade envolvida em todo o processo. Desse modo, o caminho completo inicia-se na extração da matéria-prima (por exemplo, a exploração do mineral amianto), no transporte, com os acidentes e exposições da população e trabalhadores, na sua incorporação ao processo produtivo (produção de caixas d'água e telhas de asbesto/amianto), novamente o transporte e final mente no consumo. No caso do amianto, a exposição no consumo se dá entre aqueles que manuseiam produtos finais das fábricas, como por exemplo os da construção civil e os usuários que convivem com produtos contendo amianto.

Outro bom exemplo, sempre citado, é o caso emblemático da África do Sul, onde se demonstra claramente a inter-relação entre o processo produtivo (mineração de amianto azul), o ambiente e a saúde da população, como descrito por Wagner (1991). No caso do asbesto/ amianto, os estudos sobre a exposição de trabal hadores são extensos na literatura mundial; entretanto, os estudos sobre o impacto ambiental ainda são poucos, embora se reconheça o seu potencial de biopersistência e a complexidade de sua eliminação ou disposição final, tendo em vista suas características de indestrutibilidade pelos meios tradicionais.

Estudos epidemiológicos, como o de Chang et al. (1999), determinaram o aumento de câncer de pulmão em moradores próximos a diferentes indústrias que manipulam 0 amianto em Taiwan.

Outro trabalho realizado por M agnani et al. (1995) demonstrou a ocorrência de mesotelioma pleural em 128 indivíduos, não expostos ocupacionalmente, residentes próximos a uma fábrica de fibrocimento, na região de Casale M onferrato, na Itália. Em outro estudo, 0 mesmo grupo de investigadores realizou 48 necropsias, na mesma região, de pessoas que haviam residido próximo à fábrica de cimentoamianto, e encontraram um aumento de carga de amianto e a presença de corpos asbestóticos nesse grupo. Sete pessoas apresentaram asbestose, entre elas uma professora que havia ensinado na região por 12 anos (M agnani et al., 1998).

A intervenção, tanto do Estado quanto dos movimentos sociais, está plenamente justificada, segundo Giannasi (1994), pois o amianto é um problema de Saúde Pública, já que pode causar danos não somente aos trabalhadores, como também a seus familiares, vizinhos às instalações e populações não-ocupacionalmente expostas e sequer monitoradas, e ao meio ambiente, na medida em que os resíduos com o amianto não podem ser destruídos, já que uma de suas tão decantadas propriedades é o fato de ser incombustível e incorruptível.

Portanto, o caso do amianto se apresenta claramente com forte impacto social, fugindo meramente do escopo ocupacional, pois atinge indiscriminadamente toda a sociedade, não podendo prescindir dos movimentos sociais na proteção coletiva da saúde.

\section{Ausência de políticas públicas: a dimensão social e a invisibilidade dos problemas relacionados ao amianto no Brasil}

\section{O Brasil na contramão da H istória}

Enquanto 0 amianto já foi proibido em 36 países em todas as suas formas químicas e estruturais e teve sua utilização restrita em inúmeros outros, no Brasil a fibra tóxica continua sendo explorada e utilizada em grande escala.

A Comissão das Comunidades Européias aprovou em 26/7/1999 a Diretiva 1999/77/CE, que decidiu pela proibição total do uso do amianto/asbesto em todos os países membros da União Européia, que ainda não a tivessem adotado, a partir de janeiro de 2005. Argentina, Chile e El Salvador tomaram a dianteira da proibição do amianto na América Latina, decisão que também deverá ser acompanhada em muito em breve pelo Equador e Peru.

Essas ações em ambos os hemisférios, N orte e Sul, ensejaram em 21/2/2002 que uma comissão de especialistas, reunida pela Organização das Nações Unidas em seu programa para o M eio Ambiente (UNEP/PN U M A-Programa das $\mathrm{N}$ ações Unidas para o $\mathrm{M}$ eio A mbiente) recomendasse que o comércio de todas as formas de amianto passe a ser submetido a controle prévio (PIC-Prior Informed Consent/ Consentimento Prévio Informado) pela Convenção de Roterdã, que atualmente só inclui um dos tipos de amianto, o anfibólio crocidolita (ou amianto azul). 0 amianto também foi tratado com atenção pela Convenção da Basiléia, que dispõe sobre o controle de movimentos transfronteiriços de sustâncias tóxicas, es- 
tando incluídos seus resíduos na classe dos pe rigosos e proibidos de serem exportados.

\section{0 poderoso lobby do amianto no Brasil}

A produção do amianto ganhou força sob o governo militar na década de 1970, especialmente no setor de fibrocimento (tel has e caixas d'água), quando já se iniciavam fortes pressões na Europa e Estados U nidos pelo seu banimento. Enquanto os países desenvolvidos se adiantavam para substituir o amianto, aqui novas fábricas eram instaladas, numa clara transferência de tecnologias e riscos para 0 Terceiro M undo.

Com 200 mil toneladas ao ano, o Brasil está entre os cinco maiores produtores do mundo. Diferentemente de seu parceiro comercial pela manutenção deste rentável negócio na Organização M undial do Comércio (OMC), 0 Canadá, que exporta $98 \%$ do amianto produzido para os países em desenvolvimento, $70 \%$ do amianto brasileiro é utilizado no mercado nacional. Destes $70 \%$ destinados ao mercado interno, $90 \%$ vão para a indústria da construção. M ais da metade da produção do setor é controlado por duas empresas transnacionais, SaintGobain/Brasilit (francesa) e Eternit (ex-Suíça), que se juntaram numa joint-venture, a Eterbras, em cujos países de origem o amianto já está proibido há quase uma década. As referidas empresas enfrentam processos vultosos em seus tribunais movidos pelas vítimas e seus familiares desta matéria-prima, que já foi proclamada como o "mineral mágico ou seda artificial" e que hoje é identificada como "a poeira assassina ou o mal industrial do século 20".

Essas empresas multinacionais, em nosso país, anunciaram em meados de 1999 que substituiriam 0 amianto de seu processo produtivo, acompanhando a decisão européia e as exigências do mercado global. A partir daí, vêm fazendo isso de maneira gradativa.

Já no campo do legislativo brasileiro, as ações são ainda tímidas por parte do poder público e sempre acompanhadas de debates inócuos e dos anúncios de efeitos catastróficos para a economia nacional com objetivos meramente protelatórios. Isso nos leva a temer que o "mercado" decida pôr fim a esse flagelo eque mais uma vez as políticas de Saúde Pública e sociais se curvem diante do determinismo econômico, político e mercadológico.

No caso brasileiro, até o momento, temos essa proibição aprovada e mantida em apenas dois Estados, Rio de Janeiro e Rio Grande do Sul, já que as leis de São Paulo e M ato Grosso do Sul foram derrubadas por decisão do Supremo Tribunal Federal em 8/5/2003. A pesar disso, de maneira lenta e gradual, em mais de 50 municípios brasileiros, especialmente os das regiões Sudeste e Sul, tramitam ou já há leis aprovadas proibindo os usos do amianto. Sem dúvida, mesmo que modesta, esta é uma vitória irrefutável atribuída aos movimentos sociais brasileiros, os quais iremos anal isar mais à frente. Esses grupos têm resistido bravamente aos ataques de lobistas pró-amianto nacionais e internacionais e dos políticos, especialmente do Estado de Goiás, quequerem manter a qualquer custo a exploração do amianto. 0 material constitui-se em importante fonte de receita para o Estado, sendo da ordem de $30 \%$ do total bruto de impostos arrecadados, que correspondeu a 60 milhões de Reais em 1999 (N otícias, Supremo Tribunal Federal de24/5/ 200217: 57).

\section{A constituição das redes como parte da construção da visibilidade social}

0 termo rede vem do latim retis e significa entrelaçamento de fios que se realimentam. M atemáticos, cientistas sociais, estatísticos entre outros, desde 1930, têm contribuído para o desenvolvimento do conceito de rede social como forma natural de descrever a estrutura de relações de uma população.

Barbosa et al. (2000) se referem ao conceito de rede social como um conjunto de pessoas em uma população e suas conexões. A análise de redes sociais se baseia no pressuposto da importância das relações entre unidades que interagem; isto é, as relações definidas como ligações entre unidades constituem componente fundamental das teorias de redes.

Dois exemplos clássicos de articulação solidária ou organização em rede (Collins,1998) são encontrados na Idade M édia, quando uma estrutura feudal dividia a sociedade em três ordens absolutamente hierarquizadas, o povo se organizava em "laços de solidariedade horizontal". E outro é o da articulação de judeus do mundo todo para salvar os compatriotas condenados aos campos de concentração na Europa, que simplesmente salvou milhares de pessoas do holocausto.

Segundo Collins (1988), a perspectiva das redes sociais não focaliza os atributos das uni- 
dades autônomas individuais, as associações entre esses atributos ou a utilidade de um ou mais desses atributos no sentido de predizer 0 nível do outro. Esta perspectiva visualiza as características das unidades sociais como características emergentes dos processos estruturais. Desta forma, as ligações relacionadas entre os atores envolvidos são primárias, enquanto os atributos dos atores são secundários, e o conceito de redes sociais enfatiza, ainda, que cada indivíduo tem ligação com outro indivíduo.

Segundo Whitaker (1999), uma estrutura em rede - que é uma alternativa às estruturas tradicionais piramidais de poder - corresponde também ao que seu próprio nome indica: seus integrantes se ligam horizontalmente a todos os demais, diretamente ou através dos que os cercam. 0 conjunto resultante é como uma malha de múltiplos fios, que pode se espalhar indefinidamente para todos os lados, sem que nenhum dos seus nós possa ser considerado principal ou central, nem representante dos demais. Não há um "chefe", o que há é uma vontade coletiva de realizar determinado objetivo.

Todo esse debate ainda é muito novo para a sociedade brasileira, muito mais acostumada com os sistemas tradicionalmente piramidais de poder na esfera da representação pública, através dos partidos políticos, entidades de classe, associações de moradores de bairro, etc.

O utra questão que nos remete a uma análise profunda é que a partir da constituição dessas redes e, em uma perspectiva de plena fluência sem "nós" que impeçam o fluxo da informação e da coletivização das decisões, vamos nos defrontar com outras redes que se entrelaçam, formando uma intricada figura geométrica, não mais plana e horizontal, como definida por Whitaker (1999), como por exemplo as "Redes de Redes", que se constituem em umbrellas (guarda-chuvas) e que se contrapõem, não mais dentro de sua própria estrutura, como o modelo piramidal de organização, mas na esfera pública de decisões, disputando com os poderes constituídos.

Alguns dos pressupostos que julgamos base imprescindível na estruturação das redes como resposta e desafio às elites do poder global, reforçando o poder local são: a circulação de informação (base comum de funcionamento de todo e qualquer tipo de rede); formação de seus membros (situando- os sobre os conceitos, temas e informações envolvidas no processo); criação de vínculos de solidariedade entre os membros; realização de ações em conjunto; participação livre e autônoma de seus membros. Como assinala Evers (1983), as redes devem servir, sobretudo, como ferramenta de luta contra a marginalização e contra a "necrofilia do capitalismo".

\section{A construção das redes sociais no Brasil: o caso específico do amianto}

A nossa análise se concentra em torno do amianto e suas conseqüências na saúde e vida da população exposta, direta e ocupacionalmente, e indireta, paraocupacional ou ambientalmente.

A lacuna ou vácuo criado pela ausência de representação na esfera pública fez com que grupos de excluídos pelo e para o trabal ho e outros grupos minoritários e discriminados pela prática do racismo ambiental - no nosso caso as vítimas do amianto - fossem se agrupando em torno de uma causa que Ihes era comum, ou seja, a luta pela reparação dos danos sofridos (indenização) e pelo banimento de qualquer forma de utilização do amianto no Brasil e no mundo. E isso com um objetivo único, ou seja, evitar as mazelas provocadas por esse mineral, que destrói a saúde, e, conseqüentemente, a vida daqueles que se expõem a ele.

0 movimento social respondeu com a formação da Associação Brasileira dos Expostos ao Amianto (Abrea), uma organização nãogovernamental, sem fins lucrativos, fundada em 1995 em O sasco/São Paulo. A partir daí, outros trabalhadores do amianto no Brasil tomaram iniciativas em seus Estados e fundaram filiais da Abrea no Rio de Janeiro e Bahia para lutar coletivamente por sua saúde e reivindicar seus direitos. A Abrea tem como objetivos: aglutinar trabalhadores e os expostos ao amianto em geral, cadastrar os expostos e vítimas do amianto, encaminhar os expostos para exames médicos, conscientizar a população em geral, trabalhadores e opinião pública sobre os riscos do amianto, propor ações judiciais em favor de seus associados e das vítimas em geral, integrar-se a outros movimentos sociais e ONG's pró-banimento em nível nacional e internacional e lutar para o banimento do amianto mundialmente (Abrea, 2003).

As vítimas do amianto passaram a se expressar publicamente contra o não reconhecimento de seus direitos e na defesa de seus interesses. Graças ao empenho e determinação dos membros da Abrea, hoje se reconhece no 
país a existência de, no mínimo, 2.500 vítimas, através dos processos de indenização judiciais e extrajudiciais, somente nas empresas multinacionais de cimento-amianto e da mineração. Infelizmente, esses dados, até o momento, não fazem parte da estatística oficial de doenças profissionais da Previdência Social, por falta de conexão entre os diversos poderes constituídos.

\section{Redes do banimento do amianto e de suas vítimas: terceiro setor ou contrapoderes?}

Inicialmente, cabe uma observação sobre os movimentos sociais, que, no entender dos autores, são organizados em torno de uma causa específica, constituídos criticamente contra o sistema de dominação estabelecido e não estruturados como os sistemas clássicos de representação coletiva (como partidos, sindicatos). Têm um maior questionamento da origem do problema, buscando atingir focal e globalmente os poderes constituídos.

Segundo Giannasi (2002), com a massificação globalizante do uso da Internet, as ON Gs (O rganizações Não-Governamentais), redes, ativistas e movimentos sociais em geral ganharam um aliado importantíssimo contra a hegemonia da informação e com isto puderam promover a disputa com os poderes, constituindo-se em verdadeiros contrapoderes ou "revolucionários nômades", conforme definido por H ardt e N egri (2001), subvertendo potencialmente a nova ordem capitalista.

Utilizando-se de videoconferências, listas de discussões, home pages e de todas as facilidades deste meio, principalmente a velocidade da dispersão da informação, estes "subversivos cibernáuticos" transformaram a Internet em ferramenta de luta contra a marginalização em favor dos despossuídos, buscando nivelar as relações de poder entre o local e o global. "Sabendo portar, toda ferramenta é uma arma" (H ardt e N egri, 2001), como diz a epígrafe de Ani DiFranco em "My IQ".

Em torno da questão do amianto no mundo foi constituída uma rede composta por cidadãos de todos os continentes que se dispõe a doar parte de seu tempo, voluntariamente e sem remuneração, em prol da defesa de um mundo sem amianto (asbestos free world). Foi constituída durante o Seminário Internacional sobre o Amianto: U so Controlado ou Bani- mento?, ocorrido em 28-30 de março de 1994 em São Paulo, promovido pela Fundacentro (Fundação Jorge D uprat Figueiredo de Segurança e M edicina do Trabalho) e as centrais sindicais, CUT (Central Ú nica dos Trabalhadores) e Força Sindical. Deste evento resultou a Declaração de São Paulo, documento-guia que norteia as ações da Rede em todo mundo, ação esta descentralizada em coordenações regionais, entre as quais a Rede Virtual-Cidadã pelo Banimento do Amianto na América Latina. Em 1998 foi constituído o International Ban Asbestos Secretariat (IBAS, 2003), que dá suporte a toda Rede e tem sede na Inglaterra.

Junto com a Abrea, a Rede Virtual-Cidadã pelo Banimento do Amianto para a América Latina, articulada internacionalmente com a Rede Ban Asbestos (no inglês, Ban Asbestos N etwork), constituíram-se como contraposição aos grupos hegemônicos ligados a instituições governamentais, sindicais e empresariais, que defendiam o uso seguro ou "controlado" do amianto.

Este tipo de ativismo, articulado inclusive em nível global, propõe-se a pensar localmente (definindo os problemas, necessidades e demandas) para atuar globalmente e assim gerar as mudanças necessárias.

Esses "novos" movimentos sociais surgiram no Brasil em meados da década de 1990 de maneira espontânea, empírica, anárquica, para se contrapor às necessidades momentâneas e pontuais frente à globalização da economia e à transferência de riscos dos países industrializados para os em desenvolvimento. $\mathrm{N}$ ão se situavam simplesmente como movimentos antiglobalização, mas como uma global ização que vem de baixo (globalization coming from below), isto é, vinda das bases do tecido social. Evidentemente, esta é uma forma de enfrentar os interesses hegemônicos das corporações transnacionais e dos Estados-Corporativos e por isto foram denominados de "fundamentalistas antiamianto" ou simplesmente rotulados de "fanáticos e extremistas" (Instituto do Amianto, 1994).

Os ativistas mundiais antiamianto buscam, com isso, frear os efeitos desintegradores e desarticuladores do lobby pró-amianto, que, em nome dos princípios do livre mercado, da competitividade e "da defesa do interesse generalizado e coletivo dos cidadãos", estão de fato promovendo uma das mais perversas formas de "desapropriação das oportunidades de vida", impondo um modelo de desenvolvimento 
devastador para a humanidade e praticando o racismo ambiental, quando não dão a oportunidade de escolha ao trabal hador nos países de Terceiro Mundo, que têm de decidir pelo emprego ou a saúde, quando não dão ao consumidor o direito de plena informação e de escolha (right-to-know e right-to-act) e quando sofismam o papel social de seus produtos para a população carente, al egando que sem amianto eles perecerão por falta de água potável e tetos para cobrirem seus casebres.

Em contraposição a isto, as redes e ON G's antiamianto no Brasil (Rede Virtual-Cidadã do Banimento do Amianto para a América Latina e a Abrea) e seus apoiadores buscam, sobretudo, construir um espaço de cidadania ou uma "cidadania de protesto", conforme denominado por Souza (1994).

A Rede de Informação para o Terceiro Setor (RITS) em Os Recursos da Solidariedade (RITS, 2003) define que 0 surgimento de um terceiro setor - não-governamental e não-lucrativo - redefine o Estado e o mercado. Por outro lado, o terceiro setor também se vê, ele próprio, confrontado ao desafio de qualificar e expandir suas ações de promoção de uma solidariedade eficiente.

$\mathrm{N}$ a sua análise sobre as estruturas piramidais de poder, Whitaker (1999) menciona, como uma das principais características desta forma de organização, a luta pelo poder e a competição que se estabelece em seu interior para se "subir" na pirâmide, com todas as manipulações disso decorrentes. Segundo ele, quando os adversários ou inimigos de uma organização sabem se utilizar dessas dinâmicas para dividi-las, as lutas internas podem fragilizá-las e mesmo paralisar sua ação (Whitaker, 1999).
Já nas redes, segundo W hitaker, a própria noção de gratuidade e desinteresse pessoal, essencial para o desenvolvimento da solidariedade, ganha uma dimensão social mais realista: ela pode ser entendida numa perspectiva de reciprocidade aberta, na troca de informações - que são poder - feita através da rede. As redes se contrapõem portanto à cultura do "guardar para si" e do "levar vantagem", ao permitir que, pela colocação em comum do que cada um dispõe, todos ganhem (Whitaker, 1999).

Giannasi (2002) salienta que antes de mais nada estes movimentos al ternativos - os contrapoderes ou a globalização contra-hegemônica ou que vem de baixo -, ou qualquer outra nomenclatura mais apropriada que venha a ser adotada, tentam, antes de mais nada, rediscutir o significado do trabalho, da vida e do adoecer. E também desconstruir paradigmas como a identificação do progresso com o crescimento industrial ou o desenvolvimento das forças produtivas e a concepção de política como algo que se faz através de e pelo Estado por meio de organizações hierárquicas verticalizadas (piramidais), que visam acumular o poder e exercê-lo em nome da base, sem a participação desta. Os movimentos antiamianto no Brasil, buscam na horizontalidade, solidária e global, uma nova forma de fazer valer suas posições e de fazer política, contrapondo-se à ideologia do "uso controlado do amianto".

A luta pelo fim da utilização do amianto e das inúmeras doenças provocadas por ele configura-se um movimento político comprometido com a transformação social na busca por uma sociedade mais justa, igualitária e saudável.

\section{Referências bibliográficas}

ABREA (Associação Brasileira dos Expostos ao Amianto) 2003. Disponível em <http://www.abrea.com.br>

Algranti E 2001. Epidemiologia das doenças ocupacionais respiratórias no Brasil. Epidemiologia das Doenças Respiratórias 1(3):119-143.

Barbosa M T, Byngton M RL \& Struchiner CJ 2000. M odelos dinâmicos e redes sociais: revisão e reflexões a respeito de sua contribuição para o enfrentamento do HIV. Cadernos de Saúde Pública 16(1):37-51.

Câmara VM \& Galvão LAC 1995. A patologia do trabaIho numa perspectiva ambiental, pp. 75-85. In $\mathrm{R}$ M endes (ed.). A patologia do trabalho. Editora Atheneu, São Paulo. 
Castro HA \& Gomes VRB 1997. Doenças do aparelho respiratório relacionadas à exposição ao asbesto. $\mathrm{Re}$ vista Pulmão 6(3):162-170.

Castro HA et al. 2001. Os principais métodos diagnóstico de asbestose. Revista Pulmão 4(10):38-47.

Chang HY, Chen CR \& Wang JD 1999. Risk assessment of lung cancer and mesothelioma in people living near asbestos-related factories in Taiwan. Archives of Environmental Health 3(54):194-201.

Collins R 1998. Theoretical sociology. H arcourt Brace Jovanovich, N ova York.

Evans P 1998. Globalización Contra-H egemónica: Las redes transnacionales como herramientas de lucha contra la marginalización. Contemporary Sociology 87(1):18-27.

Evers T 1983. Estatismo vs. imediatismo: noções conflitantes da política na Alemanha Federal. N ovos Estudos Cebrap 2(1):25-39.

Freitas CM 2003. Problemas ambientais, saúde coletiva e ciências sociais. Revista Ciência \& Saúde Coletiva 8(1):137-150.

Giannasi F 1994. 0 amianto no Brasil: uso controlado ou banimento? Revista brasileira de saúde ocupacional, 22:17-24.

Giannasi $F$ 2002. A construção de contrapoderes no Brasil na luta contra o amianto: a globalização por baixo. In Patologia do trabalho. (2a ed. atualizada e ampliada). 2 volumes. Ed. Atheneu, São Paulo.

Giannasi F, Scavone L \& Thébaud-M ony A 1999. Cidadania e doenças profissionais: o caso do amianto. Revista Perspectivas 22.

Hardt M \& N egri A 2001. 0 Império. (2a ed.). Editora Record, Rio de Janeiro.

IBAS (International Ban Asbestos Secretariat) 2003. Disponível em <http://www.ibas.btinternet.co.uk/>

Instituto do Amianto 1994. 0 fanatismo no banimento do amianto - uma grande desilusão. M as a que custo para a sociedade? (M imeo).

M agnani C et al. 1995. Pleural maligant mesotelhioma and non-ocupational exposure to asbestos in Casale M onferato, Italy. O ccupational Enviromental M edicine 52:362-367.
M agnani $C$ et al.1998. Asbestos lung burden and asbestosis after occupational and environmental exposure in an asbestos cement manufacturuing area: necropsy study. O ccupational Enviromental M edicine 55: 840-846.

M endes R 2001. Asbesto (amianto) e doença: revisão do conhecimento científico e fundamentação para uma urgente mudança da atual política brasileira sobre a questão. Cadernos de Saúde Pública 17(1):7-29.

Paim JS \& Filho NA 1998. Saúde coletiva: uma "nova saúde pública" ou campo aberto a novos paradigmas? Revista de Saúde Pública 32(4):299-316.

Paoli M C 1991. As ciências sociais, os movimentos sociais e a questão do gênero. N ovos Estudos CEBRAP 31 (1): 107-120.

RITS (Rede de Informação para o Terceiro Setor) 2003. Disponível em <http://www.rits.org.br/>

Selikoff I J \& Lee DHK 1978. Asbestos and disease. Academic Press, Nova York.

Souza N H B 1994. Trabalhadores pobres e cidadania: a experiência da exclusão e da rebeldia na construção civil. Tese de doutorado apresentada ao Departamento de Sociologia da Faculdade de Filosofia, Letras e Ciências H umanas da Universidade de São Paulo.

Tambellini AT \& Câmara VM 1998. A temática saúde e ambiente no processo de desenvolvimento do campo da saúde coletiva: aspectos históricos, conceituais e metodológicos. Revista Ciência \& Saúde Coletiva 3 (2):47-59.

Tarride MI 1998. Saúde pública - uma complexidade anunciada. Fiocruz, Rio de Janeiro.

Wagner JC 1991. The discovery of association between blue asbestos and mesotheliomas and the aftermath. Britsh Journal of Indusrial M édicine 48:399-403.

W hitaker F 1999. Rede: uma estrutura alternativa de organização. Disponível em <http://www.rits.org.br>

WHO (World Health Organization) 1998. Environmental H ealth Criteria 203 Chrysotile Asbesto. Geneva.

Artigo apresentado em 8/9/2003

Aprovado em 10/10/2003

Versão final apresentada em 24/11/2003 